\title{
Medullary ischemia after endovascular procedure of infrarenal aorta in a patient with dual anticoagulant and antiplatelet therapy: a case report
}

\author{
Erika D. Pérez-Riveros", Cesar A. Cardona-Montes, Carlos A. Zapata-Álvarez, Wendy L. Sotelo-Hernández and \\ Alirio R. Bastidas-Goyes
}

\begin{abstract}
Background: Medullary ischemia secondary to surgical procedures of the infrarenal aorta is an infrequent and mostly devastating complication of this procedure, and its nonspecific clinical presentation makes it difficult to promptly diagnose. Prevention measures for this complication are not yet clear; therefore, the need for anticoagulant and/or antiplatelet therapy is discussed.
\end{abstract}

Case presentation: This paper reports a case of a 69-year-old Hispanic man presenting with sudden pain and signs of ischemia on his left lower extremity 8 weeks after endovascular repair with endoprosthesis of an infrarenal aorta and left iliac aneurysm. The patient was admitted to the emergency room, where an extensive arterial thrombosis compromising the right iliac and femoral arteries was diagnosed. Dual anticoagulation and antiplatelet therapies were initiated, and therapeutic ranges were achieved. Nonetheless, the patient presented medullary ischemia by microembolization diagnosed by contrast-enhanced magnetic resonance imaging, with unsatisfactory evolution of an intracranial hemorrhagic event without documented excessive anticoagulation. The patient developed permanent pure motor deficit of his lower extremities, absence of sphincter control, and mild cognitive impairment.

Conclusions: This is a complex and extremely rare case. It is important to continue with clinical investigations that give more clarity about the onset of anticoagulation, antiplatelet therapy, and management of dual schemes to decrease the risk of complications in this type of surgical procedure.

Keywords: Spinal cord ischemia, Blood vessel prosthesis, Platelet aggregation inhibitors, Anticoagulants

\section{Introduction}

Medullary ischemia secondary to surgical procedures of the infrarenal aorta has been reported in the literature as an infrequent complication; however, when present, it can be catastrophic [1]. The diagnosis of this complication is mostly clinical and achieved with the aid of imaging [2]. In several reviews in the literature, it is considered that this event may be preventable with adequate postoperative care; however, the need for anticoagulant and/or antiplatelet therapy is discussed in several clinical studies [3]. Despite not having a clear indication, it is thought that in certain patients it is necessary to

\footnotetext{
* Correspondence: erikaperi@unisabana.edu.co; erikadayana22@gmail.com Clínica Universidad de la Sábana, Chía, Colombia
}

consider prescribing at least one antiplatelet medication in order to reduce prothrombotic risks [4]. This paper reports the case of a 69-year-old man who underwent an endovascular repair of an infrarenal aorta and left iliac aneurysm, and even after receiving anticoagulant and antiplatelet therapy, both within therapeutic ranges, he had multiple thromboembolic, ischemic, and hemorrhagic complications 8 weeks after his surgery, with permanent sequelae.

\section{Case presentation}

The patient was a 69-year-old Hispanic man with no family history of cardiovascular or hematological diseases. He was a heavy smoker with a history of 15

(c) The Author(s). 2019 Open Access This article is distributed under the terms of the Creative Commons Attribution 4.0 International License (http://creativecommons.org/licenses/by/4.0/), which permits unrestricted use, distribution, and 
pack-years. He was retired and not an alcoholic. He had a history of arterial hypertension, revascularized ischemic heart disease, and aortic valve replacement 10 years earlier, in addition to five coronary stents, chronic peripheral arterial disease of the lower limbs, and an aneurysm of the infrarenal aorta and left primitive iliac artery (Fig. 1a, b). He underwent endovascular surgery with an Endurant II stent (Medtronic, Minneapolis, MN, USA) and a successful right hypogastric artery embolization (Fig. 2a-d). There were no complications in the postoperative period; he received ambulatory anticoagulant therapy with low-molecular-weight heparin and subsequent change to warfarin, but with little adherence to the initial treatment. In addition, he received atorvastatin $40 \mathrm{mg}$ daily, acetaminophen $1 \mathrm{~g}$ every 8 hours, clonidine $150 \mathrm{mg}$ every 8 hours, losartan $50 \mathrm{mg}$ every 12 hours, nimodipine $60 \mathrm{mg}$ every 4 hours, phenytoin $300 \mathrm{mg} / \mathrm{night}$, and bisacodyl $10 \mathrm{mg}$ daily. He did not receive any antibiotics before the surgery; after the surgery, he received norfloxacin $400 \mathrm{mg}$ every 12 hours for 7 days to treat a urinary tract infection.

Two months after surgery, he was admitted to the emergency room with blood pressure of $97 / 52 \mathrm{mmHg}$, heart rate 79 beats/minute, respiratory rate 20 breaths/ minute, and temperature of $36{ }^{\circ} \mathrm{C}$. He presented with sudden pain in his lower left limb with signs of ischemia (absence of popliteal and pedis pulses, paleness and coldness of the extremity, motor and sensitivity loss), a partially normal neurological examination regarding orientation, with compromise of superficial and deep sensitivity of the lower limbs. He had laboratory test results of white blood cell count of $15,2 \times 10^{\wedge} 3 / \mathrm{uL}$, neutrophils $82 \%$, lymphocytes $17 \%$, hemoglobin $15.2 \mathrm{~g} / \mathrm{dL}$, hematocrit $44.5 \%$, platelets $154 \times 10^{\wedge} 3 / \mathrm{uL}$, blood urea nitrogen $14.3 \mathrm{mg} / \mathrm{dL}$, creatinine $0.87 \mathrm{mg} / \mathrm{dL}$, and initial international normalized ratio (INR) in subtherapeutic range (INR 1.05-1.95). He was diagnosed with an exacerbation of his chronic peripheral arterial disease with an arterial duplex of his lower limbs, showing moderate atheromatous process of lower limb arteries, with acute left femoral popliteal artery occlusion from its origin extending to the anterior and posterior tibial arteries and pedis artery. The patient was initiated on intravenous unfractionated heparin (UFH) and dual antiplatelet therapy achieving anticoagulation goals with subsequent gradual improvement of limb ischemia. After 48 hours of observation, he had a sudden pain in his lumbar region associated with absence of sphincter control and loss of strength of his lower limbs with a Medical Research Council scale score of 0/5 (complete paralysis). Contrast-enhanced magnetic resonance imaging (MRI) was performed, which revealed extensive dorsal myelopathy from T3-T4 to T11-T12 (Fig. 3a-d) of compressive and/or ischemic nature, and extensive spinal cord infarction was determined. Twenty-four hours later, despite the established antihypertensive treatment, he presented with a hypertensive emergency with acute target organ damage. Anti-ischemic management was initiated, and it was decided to stop heparin due to possible excessive anticoagulation. During the evolution of this presentation, he had headaches; hence, cerebral computed tomographic angiography was performed, which showed supra- and infratentorial intraparenchymal hemorrhage and thalamic hematoma. An intensive care unit stay as well as rehabilitation for the subsequent management of his symptoms and stabilization of comorbidities was required.

After commonly agreeing with the family, he was discharged for home healthcare planning. When discharged, the patient's pure motor deficit in his lower extremities persisted, along with absence of sphincter control and presence of mild cognitive impairment, specifically in memory. Seven months after outpatient treatment, with progressive worsening of complications of his disease with depression, recurrent infections, and skin ulcers, the patient died.

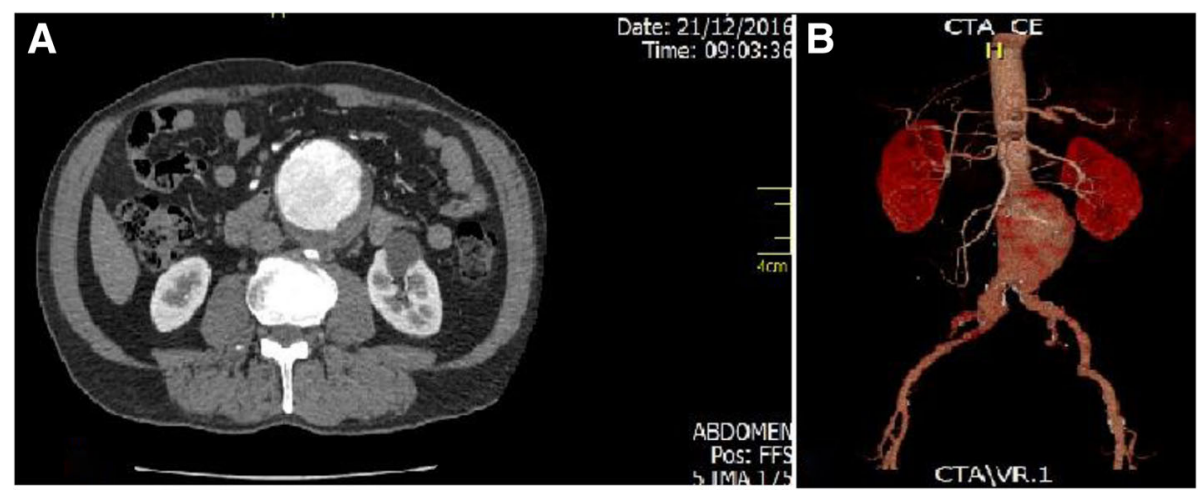

Fig. 1 a Abdominal computed tomographic (CT) scan in transverse section prior to endovascular surgery. An infrarenal aortic aneurysm is observed. b CT angiography showing infrarenal aortic aneurysm 

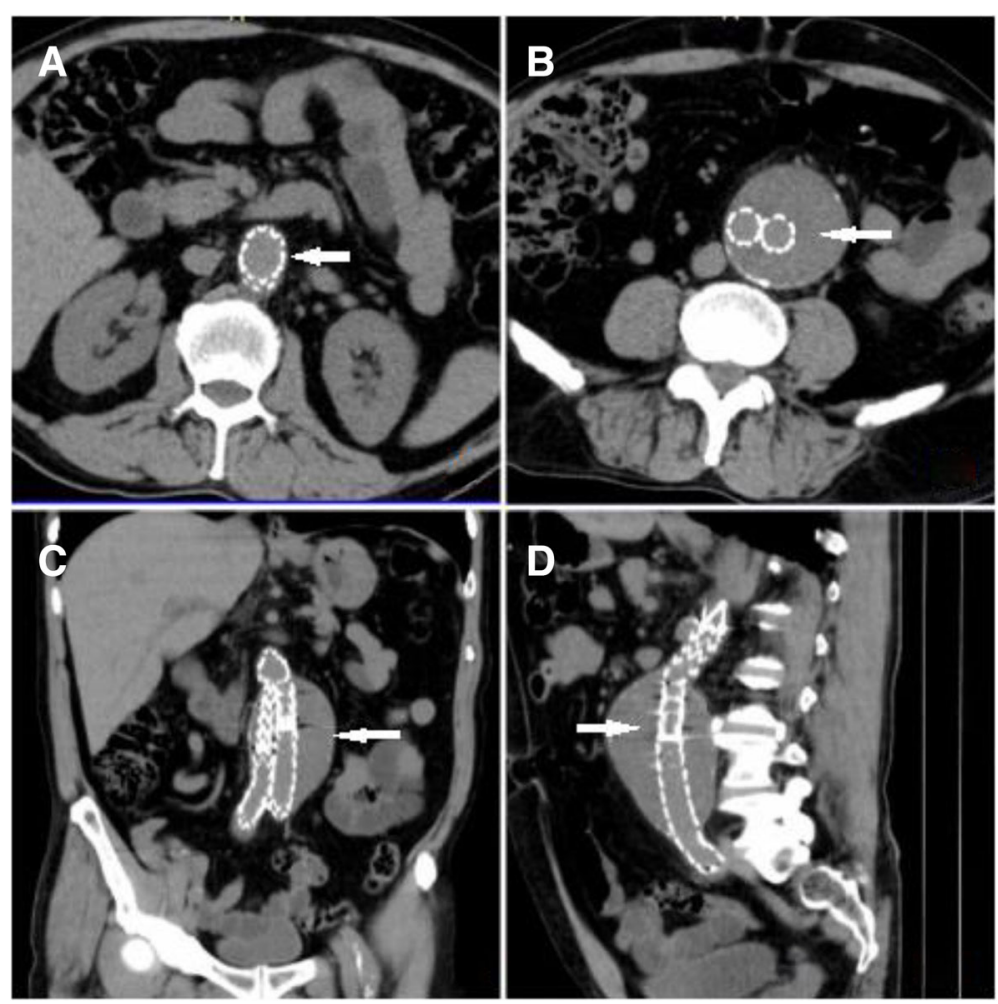

Fig. 2 a Abdominal computed tomography transverse section after endovascular surgery. Endovascular prosthesis implantation is observed. $\mathbf{b}$ Aneurysmal stent implantation is observed. c Coronal section with implantation of prosthesis. $\mathbf{d}$ Sagittal section with implant of prosthesis. The prosthesis is marked with white arrows

\section{Discussion}

A 69-year-old man with multiple comorbidities had an infrarenal aortic aneurysm treated with endovascular surgery and hypogastric artery embolization without complications. He received anticoagulant therapy with little adherence to the treatment. Two months after surgery, he was admitted to the emergency room with an exacerbation of his chronic peripheral arterial disease. Treatment with intravenous UFH and dual antiplatelet therapy achieved anticoagulation goals. However, 48 hours later, he was diagnosed with an extensive dorsal myelopathy of compressive and ischemic nature, as well as an extensive spinal cord infarction, despite the management with dual anticoagulation and antiplatelet therapy, making this case report an important contribution to the medical literature. There is no specific data for patients who undergo this type of endovascular correction; therefore, it is necessary to continue with clinical investigations that provide more clarity about the onset of anticoagulation, antiplatelet management of dual schemes with the purpose of decreasing the risk of complications.

The endovascular treatment for an aortic aneurysm, both thoracic and abdominal, has increased due to the multiple benefits it offers, being a minimally invasive technique that does not require general anesthesia. The costs associated with the intervention are minor, and the intervention can be performed by different specialties such as endovascular surgery or interventional radiology [1]. However, some reports indicate concern with the high probability of generating embolization at any level secondary to the endovascular approach compared with open surgery [5].

Medullary ischemia after a surgical intervention in the infrarenal aorta, according to some cohorts, has an extremely low reported incidence, up to $0.21 \%$ [3]; however, in other reports, it has reached $13.8 \%$, increasing if the patient presents with risk factors such as hypotension during surgery $[6,7]$, history of repair with a previous endoprosthesis, size of the aneurysm, and surgical technique [8]; using minimally invasive strategies such as the use of catheters and other artifacts can have prothrombotic effects [5]. It is believed that neurological damage after an aortic intervention is secondary to hypoxic damage of the spinal cord and the generation of free radicals in addition to reperfusion edema [9].

The clinical presentation of this complication is unspecific. It has been described that patients arrive 

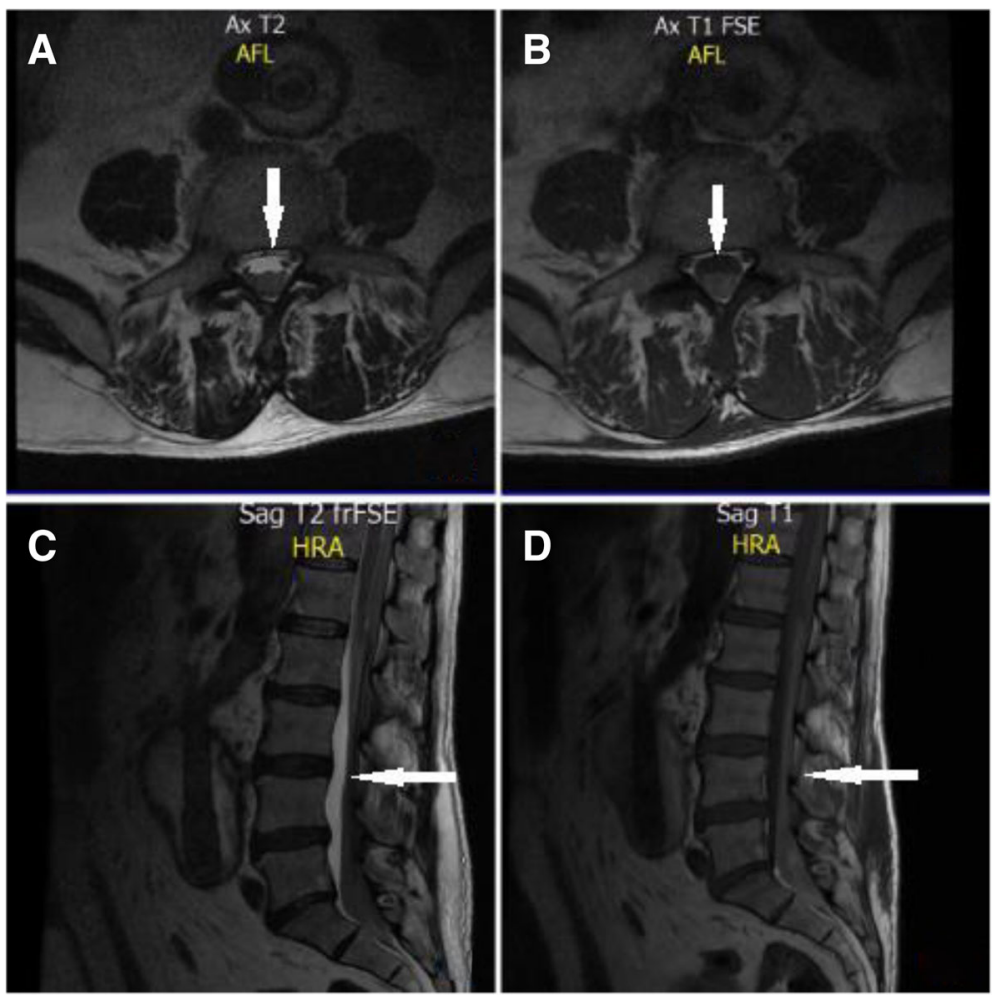

Fig. 3 a Magnetic resonance imaging (MRI) T2-weighted transverse section. A hyperintensity zone is observed showing spinal infarction at the T10 level. b MRI T1-weighted hypointensity showing spinal cord infarction. c MRI T2-weighted sagittal section showing extension of the medullary infarction with hyperintensity zone. $\mathbf{d}$ MRI T1-weighted image showing extension of the medullary infarction with hypointensity zone. The area of infarction is indicated by the white arrow

with symptoms that suggest abdominal disease because many cases start with abdominal pain associated with nausea, vomiting, and low back pain, which confuses the clinical presentation with a wide range of diagnostic possibilities of abdominal origin $[10,11]$. Subsequently, the neurological compromise is generated; however, the onset of this compromise is variable [12]. In one case, it was reported that complete paraplegia was established within the first 18 hours of admission to the emergency room [13], and other clinical cases report that the appearance of this complication was later, between 2 and 10 months after the intervention [14, $15]$.

The diagnosis of this complication is confirmed by imaging, with MRI being the best tool available with a very high specificity [2]; however, not all cases present a visible alteration on the MRI scan, and it should be suspected on the basis of the patient's clinical presentation [15]. The diagnosis of spinal cord ischemia in a patient undergoing abdominal aneurysm repair with stent placement is an interesting clinical challenge. In our patient's case, he was not in therapeutic anticoagulation ranges at admission, and despite initiating anticoagulant and antiplatelet treatment obtaining early therapeutic goal values, he finally presented with the ischemic event at the spinal level associated with a hemorrhagic cerebrovascular event.

\section{Conclusion}

Several ideal conditions to minimize the risk of complications in patients undergoing this type of procedure have been proposed in the literature; nevertheless, there is no clarity on the need or indications for the use of anticoagulant or antiplatelet therapies with good clinical evidence in this type of patient. However, it is considered that patients should receive treatment with at least one antiplatelet medication after surgery to reduce potential risks associated with it. In this regard, the most frequently used antiplatelet agents, aspirin and clopidogrel, have been discussed because both have shown considerable effects in the reduction of ischemic events [4]. However, there is no specific data for patients who have undergone this type of endovascular correction; therefore, it is necessary to continue with clinical investigations that give more clarity about the onset of anticoagulation and antiplatelet management in dual schemes with the purpose of decreasing the risk of complications. 


\section{Acknowledgements}

Not applicable.

\section{Authors' contributions}

EP conceived of the case report; acquired, analyzed, and interpreted data; and wrote the case report. CC acquired, analyzed, and interpreted data and wrote the case report. CZ acquired, analyzed, and interpreted data. WS acquired, analyzed, and interpreted data. AB critically revised the manuscript. All authors read and approved the final manuscript.

\section{Funding}

In relation to this article, the authors did not participate in any open calls or receive any financial support from their educational institution or from any other entity during the development of the study. Therefore, they did not receive any research funding, nor are they currently receiving any research funding; thus, there are no competing interests.

\section{Availability of data and materials}

Data sharing is not applicable to this article, because no datasets were generated or analyzed during the current study.

\section{Ethics approval and consent to participate}

Approval by the ethics committee was not necessary, because diagnostic procedures and treatments were performed according to standard clinical care [16]. The patient signed an institutional informed consent for receiving treatments.

\section{Consent for publication}

Written informed consent was obtained from the patient for publication of this case report and any accompanying images [17]. A copy of the written consent is available for review by the Editor-in-Chief of this journal.

\section{Competing interests}

The authors declare that they have no competing interests.

Received: 8 October 2018 Accepted: 19 June 2019

Published online: 05 August 2019

\section{References}

1. Maldonado TS, Rockman CB, Riles E, Douglas D, Adelman MA, Jacobowitz GR, Riles TS. Ischemic complications after endovascular abdominal aortic aneurysm repair. J Vasc Surg. 2004;40(4):703-10.

2. Defraigne JO, Otto B, Sakalihasan N, Limet R. Spinal ischaemia after surgery for abdominal infrarenal aortic aneurysm: diagnosis with nuclear magnetic resonance. Acta Chir Belg. 1997;97(5):250-6.

3. Buth J, Harris PL, Hobo R, van Eps R, Cuypers P, Duijm L, Tielbeek X. Neurologic complications associated with endovascular repair of thoracic aortic pathology: incidence and risk factors. A study from the European Collaborators on Stent/Graft Techniques for Aortic Aneurysm Repair (EUROSTAR) Registry. J Vasc Surg. 2007:46(6):1103-11. e2

4. Saratzis A, Saratzis N, Melas N, Kiskinis D. Pharmacotherapy before and after endovascular repair of abdominal aortic aneurysms. Curr Vasc Pharmacol. 2008;6(4):240-9

5. Rockman CB, Riles TS, Landis R. Lower extremity paraparesis or paraplegia subsequent to endovascular management of abdominal aortic aneurysms. J Vasc Surg. 2001;33(1):178-80.

6. Amato ACM, Stolf NAG, Amato ACM, Stolf NAG. Anatomia da circulação medular. J Vasc Brasileiro. 2015;14(3):248-52.

7. Wikinski JA, Salqueiro C. The artery of Adamkiewicz and its role in medullar irrigation [in Spanish]. Rev Arg Anest. 2003;61(3):170-81. https://www. anestesia.org.ar/search/articulos_completos/1/1/625/c.pdf

8. Chiesa R, Melissano G, Marrocco-Trischitta MM, Civilini E, Setacci F. Spinal cord ischemia after elective stent-graft repair of the thoracic aorta. J Vasc Surg. 2005:42(1):11-7.

9. Oudega M. Molecular and cellular mechanisms underlying the role of blood vessels in spinal cord injury and repair. Cell Tissue Res. 2012;349(1):269-88.

10. Rodríguez-Baeza A, Muset-Lara A, Rodríguez-Pazos M, Domenech-Mateu JM. Anterior spinal arteries: origin and distribution in man. Acta Anat. 1989; 136(3):217-21.

11. Melissano G, Bertoglio L, Rinaldi E, Leopardi M, Chiesa R. An anatomical review of spinal cord blood supply. J Cardiovasc Surg. 2015;56(5):699-706.
12. Riess KP, Gundersen SB, Ziegelbein KJ. Delayed neurologic deficit after infrarenal endovascular aortic aneurysm repair. Am Surg. 2007;73(4):385-7.

13. Cho JS, Rhee RY, Makaroun MS. Delayed paraplegia 10 months after endovascular repair of thoracic aortic aneurysm. J Vasc Surg. 2008:47(3): 625-8.

14. Reid JA, Mole DJ, Johnston LC, Lee B. Delayed paraplegia after endovascular repair of abdominal aortic aneurysm. J Vasc Surg. 2003;37(6):1322-3.

15. Goldstein L, Rezayat C, Shrikhande GV, Bush HL. Delayed permanent paraplegia after endovascular repair of abdominal aortic aneurysm. J Vasc Surg. 2010;51(3):725-8.

16. Ministerio de Salud. Resolución número 8430 de 1993: Por la cual se establecen las normas científicas, técnicas y administrativas para la investigación en salud. https://www.minsalud.gov.co/sites/rid/Lists/ BibliotecaDigital/RIDE/DE/DIJ/RESOLUCION-8430-DE-1993.PDF. Accessed 29 Sept 2017.

17. 2019 Asociación Médica Mundial. Declaración de Helsinki de la AMM Principios Éticos para las Investigaciones Médicas en Seres Humanos. AMM; 2015.

\section{Publisher's Note}

Springer Nature remains neutral with regard to jurisdictional claims in published maps and institutional affiliations.

\section{Ready to submit your research? Choose BMC and benefit from:}

- fast, convenient online submission

- thorough peer review by experienced researchers in your field

- rapid publication on acceptance

- support for research data, including large and complex data types

- gold Open Access which fosters wider collaboration and increased citations

- maximum visibility for your research: over $100 \mathrm{M}$ website views per year

At BMC, research is always in progress.

Learn more biomedcentral.com/submissions 